\title{
Person-centered care in Norwegian nursing homes and its relation to organizational factors and staff characteristics: a cross-sectional survey
}

\author{
Irene Røen, ${ }^{1} \phi$ yvind Kirkevold, 1,2,3 Ingelin Testad, 4,5,6 Geir Selbæk, 1,2,7 \\ Knut Engedal ${ }^{2}$ and Sverre Bergh ${ }^{1,2}$ \\ ${ }^{1}$ Centre for Old Age Psychiatric Research, Innlandet Hospital Trust, Ottestad, Norway \\ ${ }^{2}$ Norwegian National Advisory Unit on Ageing and Health, Vestfold Hospital Trust, Tonsberg, Norway \\ ${ }^{3}$ Department of Health Science in Gjøvik, Norwegian University of Science and Technology (NTNU), Gjøvik, Norway \\ ${ }^{4}$ Centre for Age-Related Medicine - SESAM, Stavanger University Hospital, Stavanger, Norway \\ ${ }^{5}$ Department of Old Age Psychiatry, Institute of Psychiatry, Psychology \& Neuroscience, King's College London, London, UK \\ ${ }^{6}$ Medical School, St Luke's Campus, University of Exeter, Exeter, UK \\ ${ }^{7}$ Faculty of Medicine, University of Oslo, Oslo, Norway
}

ABSTRACT

Background: Person-centered care (PCC) is regarded as good quality care for persons with dementia. This study aimed to explore and understand the association between PCC and organizational, staff and unit characteristics in nursing homes (NHs).

Methods: Staff from $175 \mathrm{NH}$ units in Norway $(\mathrm{n}=1,161)$ completed a survey, including measures of PCC and questions about staff characteristics and work-related psychosocial factors. In addition, data about organizational and structural factors and assessment of the physical environment in the units were obtained. The distribution of these factors in regular units (RUs) and special care units (SCUs) is described, and the differences between the two types of units are analyzed. Furthermore, multilevel linear regression analyses explored the extent to which variables were associated with PCC.

Results: Higher levels of PCC were associated with a greater job satisfaction, three years or more of healthrelated education, a lower level of quantitative demands and role conflict, a higher level of perception of mastery, empowering leadership, innovative climate and perception of group work, in addition to the type of unit and the physical environment in the NH unit designed for people with dementia. SCU and staff job satisfaction explained most of the variation in PCC.

Conclusion: This study shows an association between PCC and organizational, staff and unit characteristics in NH. These findings indicate that providing PCC in NH care is closely linked to how the staff experiences their job situation in addition to both organizational and structural factors and the physical environment. Attention needs to be given to such factors when planning $\mathrm{NH}$ care.

Key words: cross-sectional, nursing home, person-centered care, organizational factors, job satisfaction, physical environment

\section{Introduction}

Dementia is a syndrome caused by a variety of brain disorders, which leads to cognitive decline and decreased function in the activities of daily living. The syndrome is usually chronic and progressive in nature. As dementia increases in severity, the need for institutionalization increases, and more than

Correspondence should be addressed to: I. Røen, Centre for Old Age Psychiatric Research, Innlandet Hospital Trust, p.b.68, 2312 Ottestad, Norway. Phone: +47 90652165. Email: irroee@sykehuset-innlandet.no. Received 9 Aug 2017; revision requested 27 Sep 2017; revised version received 31 Oct 2017; accepted 31 Oct 2017. First published online 4 December 2017.
$80 \%$ of Norwegian nursing home $(\mathrm{NH})$ patients have dementia (Selbaek et al., 2007).

Furthermore, dementia is a condition compounded of the personality of the person with dementia, and his or her physical health, life story, neurologic impairment, and social psychology, all preserving the person's personhood (Kitwood, 1997). According to Kitwood (1977), the person with dementia and their psychological needs is the focus of the care and treatment; person-centered care (PCC) (Kitwood, 1997) rather than the person's disease (Edvardsson and Innes, 2010). PCC is widely accepted as good-quality care for persons with 
dementia in $\mathrm{NH}$ and is a guiding principle in care services (Brooker, 2004; Li and Porock, 2014; Manthorpe and Samsi, 2016). There is an increase in the literature evaluating psychosocial interventions and PCC ( $\mathrm{Li}$ and Porock, 2014; Testad et al., 2014) showing significant benefits on decreasing behavioral symptoms (Chenoweth et al., 2009), psychotropic medication use (Fossey et al., 2006), increase in mood (Brooker et al., 2011), and health-related quality of life (Ballard et al., 2015) in persons with dementia in longterm care. Theories for implementing PCC have been developed over the years, such as the VIPS framework by Brooker (2004). This framework constitutes four major elements; $V$ stands for valuing people with dementia and those who care for them; $I$ for treating people as individuals; $P$ for looking at the world from the perspective of the person with dementia; and $S$ for a positive social environment in which the person living with dementia can experience relative well-being (Brooker, 2004).

In PCC, the relationship between $\mathrm{NH}$ staff and the person with dementia is essential (Wilberforce et al., 2016), and consequently, the staff's attitude and work methods are important (Anderson et al., 2016). Several factors have in previous studies been associated with PCC, such as job satisfaction and capacity to provide individualized care (van den Pol-Grevelink et al., 2012; Brownie and Nancarrow, 2013), gender, beliefs about personhood in dementia, burnout, collaboration in care, the physical environment, the social environment of care (Hunter et al., 2015), and the psychosocial factors at work (Testad et al., 2010). A recent review article concluded that the physical environment in care settings is important for improving the patients' quality of life and quality of care practices (Chaudhury et al., 2017). Essential aspects of quality of life and care include the influence of unit size, the spatial layout, its homelike character, sensory stimulation, and specific areas for dining, bathing, and outdoor activities, all of which emphasize the relationship between the therapeutic physical environment, organizational factors, and care practices (Chaudhury et al., 2017). Although the published work on PCC is quite substantial, the number of included respondents is low and the need for larger studies is warranted. Furthermore, insight on how organizational structures can stimulate or hinder person centeredness in staff and whether levels of person centeredness correlate with individual staff variables, such as education, clinical experience, job satisfaction, and experience of organizational variables, such as type of ward (regular unit (RU) or special care unit (SCU)), unit size, leadership, staff-to-patient ratios, and physical environment, is needed.

Thus, we designed this study to explore and understand the association between PCC, assessed with the Person-centered Care Assessment Tool (P-CAT), and organizational, $\mathrm{NH}$ staff and unit characteristics.

\section{Methods}

\section{Study design and sample}

This is a cross-sectional study, with a convenience sample of $175 \mathrm{NH}$ units from $45 \mathrm{NHs}$ in 29 municipalities in four Norwegian counties. An NH unit participating in the study was defined as a group of patients living together with a common living area and having their own care staff during the daytime. NH staff, which the head nurse defined as those familiar to the care provided and the structural and organizational conditions in the unit, were considered eligible for the study.

\section{Data collection}

The data were collected during the period from October 2013 to December 2014. Three case report files (CRF), including both a standardized questionnaire and questions developed for this study by the research group, were constructed; one to the $\mathrm{NH}$ manager, one to the head nurse of the unit, and one to the NH staff. The members of the research group all have wide experience in both clinical work and research projects in NHs. The questions developed by the research group for the study were based on factors identified in the literature referring to organizational and structural factors, such as culture, leadership, management, staff education, staffing levels, and physical environment.

\section{Measures}

\section{Person-centered care}

Several tools have been developed to assess PCC (de Silva, 2014; Wilberforce et al., 2016), but the P-CAT (Edvardsson et al., 2010) is the only tool designed for self-assessing PCC by staff in long-term care facilities, which has been tested beyond the initial development stages (Wilberforce et al., 2016). The Norwegian version of the P-CAT has satisfactory psychometric properties for the use in a nursing home-care setting (Rokstad et al., 2012) and was chosen in this study. The P-CAT consists of 13 items expressed as statements about the content of care, the environment, and the organization, formulated to measure staff 
Textbox 1. Organizational and psychosocial factors*

\begin{tabular}{|c|c|}
\hline Subscales & QPS-Nordic items \\
\hline Quantitative demands & $\begin{array}{l}\text { - Is your work load irregular so that the work piles up? } \\
\text { - Do you have to work overtime? } \\
\text { - Is it necessary to work at a rapid pace? } \\
\text { - Do you have too much to do? }\end{array}$ \\
\hline$\overline{\text { Decision demands }}$ & $\begin{array}{l}\text { - Does your work require quick decisions? } \\
\text { - Does your work require maximum attention? } \\
\text { - Does your work require complex decisions? }\end{array}$ \\
\hline Learning demands & $\begin{array}{l}\text { - Are your work tasks too difficult for you? } \\
\text { - Do you perform work tasks for which you need more training? } \\
\text { - Does your job require that you acquire new knowledge and new skills? }\end{array}$ \\
\hline Perception of mastery & $\begin{array}{l}\text { - Are you content with the quality of the work you do? } \\
\text { - Are you content with the amount of work that you get done? } \\
\text { - Are you content with your ability to solve problems at work? } \\
\text { - Are you content with your ability to maintain a good relationship with your coworkers at } \\
\text { work? }\end{array}$ \\
\hline Empowering leadership & $\begin{array}{l}\text { - Does your immediate superior encourage you to participate in important decisions? } \\
\text { - Does your immediate superior encourage you to speak up, when you have different opinions? } \\
\text { - Does your immediate superior help you develop your skills? }\end{array}$ \\
\hline Fair leadership & $\begin{array}{l}\text { - Does your immediate superior distribute the work fairly and impartially? } \\
\text { - Does your immediate superior treat the workers fairly and equally? } \\
\text { - Is the relationship between you and your immediate superior a source of stress to you? }\end{array}$ \\
\hline Role clarity & $\begin{array}{l}\text { - Have clear, planned goals and objectives been defined for your job? } \\
\text { - Do you know what your responsibilities are? } \\
\text { - Do you know exactly what is expected of you at work? }\end{array}$ \\
\hline Role conflict & $\begin{array}{l}\text { - Do you have to do things that you feel should be done differently? } \\
\text { - Are you given assignments without adequate resources to complete them? } \\
\text { - Do you receive incompatible requests from two or more people? }\end{array}$ \\
\hline Innovative climate & $\begin{array}{l}\text { - Do workers take initiatives at your workplace? } \\
\text { - Are workers encouraged to think of ways to do things better at your workplace? } \\
\text { - Is there sufficient communication in your department? }\end{array}$ \\
\hline Perception of group work & $\begin{array}{l}\text { - Do you appreciate belonging to this group or team? } \\
\text { - Is your group or team work flexible? } \\
\text { - Is your group or team successful at problem solving? }\end{array}$ \\
\hline
\end{tabular}

*Thirty-two QPS-Nordic items, distributed in 10 scales were used in the study. Each scale consists of 3 or 4 items, giving a subscale score of 3-15 or $4-20$.

perceptions of the practice in the unit where they work. The participants indicate on a five-point Likert scale ranging from 1 (disagree completely) to 5 (agree completely) how they perceive the care in the unit. The total score ranges from 13 to 65 , where higher scores indicate a higher level of PCC.

\section{NH staff factors}

$\mathrm{NH}$ staff data were obtained through questionnaires. The questionnaire contained demographic information about the participants, such as age, gender, Norwegian as a first language, number of years of health-related and relevant continuing education, experience in the current job, and percentage of full-time position.

Work-related psychosocial factors were assessed with the General Nordic Questionnaire for Psychosocial and Social Factors at Work (QPSNordic), covering essential social and psychological factors at work (Dallner et al., 2000). Of the 129 items in QPS-Nordic, 11 are background items, 38 are single items, and 80 are distributed in 13 scales. In this study, 32 items distributed in the following 10 scales were included: quantitative demands, decision demands, learning demands, perception of mastery, empowering mastership, fair leadership, role clarity, role conflict, innovative climate, and perception of group work. Respondents indicated how relevant each statement was for their situation on a five-point Likert scale from 1 (very seldom or never) to 5 (very often or always). Each scale consists of 3 or 4 items, giving a subscale score of 3-15 or $4-20$ (see textbox 1 ).

A single question about general job satisfaction was added: "How will you describe your general experience of your job satisfaction?" The alternatives were "very bad - bad - unsure - quite good - good - excellent." 
To ensure staff anonymity, the head nurse did not have access to the staffs' answers in the questionnaires, with $\mathrm{NH}$ staff returning the questionnaire in a stamped envelope directly to the researchers.

\section{NH unit characteristics}

The following data about organizational and structural factors in the $\mathrm{NH}$ unit were obtained through a questionnaire distributed to the head nurse of the 175 units: type of unit (SCU or RU); the unit size (number of patients); the daytime staff/patient ratio (the number of NH staff working per patient during the daytime); the number of units per head nurse; and the number of hours the nursing home physician was working per patient per week in the nursing home/unit. To categorize $\mathrm{NH}$ units as either RU or SCU, we used the definition of SCU from the Therapeutic Environment Screening Survey for Nursing Home (TESS-NH) (Sloane et al., 2002): an SCU must be physically separated from the rest of the facility by closed doors or it is free-standing, and the unit must self-designate the unit as a specialized dementia care unit. In addition, the unit must meet two of the following three criteria: (1) the unit serves a population in which $75 \%$ or more of the residents have a diagnosis of Alzheimer's disease or related dementias; (2) unit programming and activities are dementia specific; or (3) the staff is trained in dementia care. $\mathrm{NH}$ units not fulfilling this SCU definition were defined as RUs, including regular somatic units, short-time units, and rehabilitation units.

\section{Physical environment}

To assess the physical environment of the unit, we used the Special Care Unit Environmental Quality Scale (SCUEQS), which is a summary scale embedded in the Therapeutic Environment Screening Survey for Nursing Homes (TESS-NH) (Sloane et al., 2002). TESS-NH was translated into Norwegian and back-translated according to the procedures described by Acquadro et al.(1996). Three translators, two medical doctors, and one registered nurse translated the American version of TESS-NH into Norwegian. These translations were aggregated into one Norwegian version, and a faculty research group agreed on a preliminary version. This version was translated back into English by Allegro Language Services. The English back-translated version was sent to Sloane, who developed the original TESS-NH, to get her comments. The final Norwegian version of TESS$\mathrm{NH}$ was agreed upon after a revision based on Sloane's responses and a discussion in the research group. The Norwegian version is not tested for psychometric properties. The TESS-NH contains 84 discrete items and one global rating and was developed to describe the ability of physical environments in $\mathrm{NHs}$ to address therapeutic goals for persons with dementia. The SCUEQS consists of 18 of the TESS-NH items and measures maintenance, cleanliness, safety, lighting, physical appearance/home likeness, orientation/cueing, and noise (Sloane et al., 2002). Scores range from 0 to 41 , where higher scores indicate a better physical environment.

\section{Statistical analyses}

IBM SPSS Statistics for Windows, version 23.0 (Armonk, NY: IBM Corp.) was used to perform descriptive statistics of P-CAT scores, QPSNordic and quality indicators, and staff and unit characteristics.

Of the 1,161 respondents, 77 had missing data on at least one P-CAT item and imputation was performed on cases with fewer than $50 \%$ missing values (6 at most). Four respondents had missing data on more than six P-CAT items, and data were not imputed. The empirical distribution for each item in the scale was generated. A random number was drawn from that distribution and used to replace the missing value. The process was repeated until all missing values were imputed. This algorithm mimics the bootstrap described by Efron and Tibshirani (1994).

As data were on two levels (unit and staff level), MLwiN version 2.36 (Centre for Multilevel Modeling, University of Bristol) was used to check for a clustering effect (Intra-Class Correlation (ICC)) of the units. After a clear cluster effect was found, three multilevel linear regression models were built using P-CAT sum scores as the dependent variable. Independent variables were added to the model in blocks: NH-staff characteristics (model 1), QPS-Nordic (model 2), and variables collected at unit level (level 2, model $3)$. The multilevel analysis generates two different values for variance $\sigma_{\mathrm{en}}^{2}$ for between groups and $\sigma_{\mathrm{un}}^{2}$ for within groups, and with this the proportion of the ICC explained by the models $\left(\mathrm{R}_{2}^{2}\right)$ and of the portion of variance within groups $\left(\mathrm{R}_{1}^{2}\right)$ were calculated at each step.

\section{Results}

\section{Staff characteristics and work-related psychosocial factors}

Characteristics of nursing staff are presented in Table 1 . The total staff response rate was $67.5 \%$. 
Table 1. Characteristics of nursing staff $n=1,161$

\begin{tabular}{|c|c|}
\hline & $\mathrm{N} / \%$ \\
\hline Female Gender $\mathrm{n}=1,098$ & $1,061 / 96.6$ \\
\hline Norwegian as first language $n=1,113$ & $1,023 / 91.9$ \\
\hline \multicolumn{2}{|l|}{ Age $n=1,136$} \\
\hline$<20$ & $8 / 0.7$ \\
\hline $20-29$ & $155 / 13.6$ \\
\hline $30-39$ & $187 / 16.5$ \\
\hline $40-49$ & $295 / 26.0$ \\
\hline $50-59$ & $346 / 30.5$ \\
\hline $60-67$ & $133 / 11.7$ \\
\hline$>67$ & $12 / 1.1$ \\
\hline \multicolumn{2}{|l|}{ Years of health-related education $n=1,157$} \\
\hline$\geq 3$ & $346 / 29.9$ \\
\hline$<3$ & $811 / 70.1$ \\
\hline \multicolumn{2}{|l|}{ Relevant continuing education $\mathrm{n}=1,161$} \\
\hline Yes & $318 / 27.4$ \\
\hline No & $843 / 72.6$ \\
\hline \multicolumn{2}{|l|}{ Experience in current job $\mathrm{n}=1,123$} \\
\hline$<1$ year & $84 / 7.5$ \\
\hline $1-4.99$ years & $262 / 23.3$ \\
\hline $5-14.99$ years & $457 / 40.7$ \\
\hline 15 years and more & $320 / 28.5$ \\
\hline Staff working at least $75 \%$ of full-time $\mathrm{n}=1,151$ & $700 / 60.8$ \\
\hline \multicolumn{2}{|l|}{ Job satisfaction $n=1,151$} \\
\hline Very poor & $5 / 0.4$ \\
\hline Poor & $18 / 1.6$ \\
\hline Unsure & $38 / 3.3$ \\
\hline Quite good & $293 / 25.5$ \\
\hline Good & $550 / 47.8$ \\
\hline Excellent & $247 / 21.5$ \\
\hline QPS-Nordic ${ }^{1}$ subscales $^{2}$ & $\mathrm{n} /$ mean $\left(\mathrm{SD}^{3}\right)$ \\
\hline QPS-N, quantitative demands (4 items) & $1,149 / 11.23(2.84)$ \\
\hline QPS-N, decision demands (3 items) & $1,149 / 10.10(1.99)$ \\
\hline QPS-N, learning demands (3 items) & $1,149 / 7.21(1.76)$ \\
\hline QPS-N, perception of mastery (4 items) & $1,149 / 16.24(1.93)$ \\
\hline QPS-N, empowering leadership (3 items) & $1,150 / 8.74(2.96)$ \\
\hline QPS-N, fair leadership (3 items) & $1,151 / 11.87(2.66)$ \\
\hline QPS-N, role clarity (3 items) & $1,151 / 13.00(1.95)$ \\
\hline QPS-N, role conflict (3 items) & $1,151 / 7.38(2.13)$ \\
\hline QPS-N, innovative climate ( 3 items) & $1,153 / 11.57(2.10)$ \\
\hline QPS-N, perception of group work (3 items) & $1,145 / 12.12(2.01)$ \\
\hline
\end{tabular}

${ }^{1}$ QPS-Nordic $=$ the General Nordic Questionnaire for Psychosocial and Social Factors at Work.

${ }^{2}$ QPS-Nordic subscales each consist of 3 or 4 items, giving a subscale score of 3-15 or 4-20.

${ }^{3} \mathrm{SD}=$ standard deviation.

The mean staff response rate within the units was $70.7 \%$ (SD 20.3\%), indicating that the response rates were lower in the large units. Nearly all the $\mathrm{NH}$ staffs were female $(96.6 \%), 56.4 \%$ were between 40 and 59 years old, and $91.9 \%$ had Norwegian as their first language. Most of the staff $(60.8 \%)$ had a position of $75 \%$ of full time or more, $29.9 \%$ had 3 years or more of healthrelated education, and $27.4 \%$ had received relevant continuing education. Regarding work experience, the largest group was those who had worked
5-15 years at the NH unit (49.7\%). Finally, $69.2 \%$ rated their job satisfaction as good or excellent.

\section{Unit characteristics and person-centered care assessment}

All leaders of the units except one returned the questionnaire, giving a response rate of $99.5 \%$. Of the 175 units, $62(35.4 \%)$ were SCUs. Table 2 presents differences between the RUs and the SCUs in the number of beds, the physical 
Table 2. Unit ${ }^{1}$ characteristics and P-CAT score in regular and special care units

\begin{tabular}{|c|c|c|c|c|}
\hline VARIABLES & $\begin{array}{l}\operatorname{ALL} N / M E A N \\
\left(S^{2}\right)\end{array}$ & $\begin{array}{l}\text { REGULAR UNIT } \\
\text { N/MEAN (SD) }\end{array}$ & $\begin{array}{l}\text { SPECIAL CARE } \\
\text { UNIT N/MEAN (SD) }\end{array}$ & p-VALUE \\
\hline Number of beds in unit & $175 / 10.86(5.68)$ & $113 / 12.16(6.42)$ & $62 / 8.48(2.72)$ & $<0.001^{5}$ \\
\hline Staff/patient ratio & $174 / 0.32(0.09)$ & $113 / 0.30(0.06)$ & $61 / 0.35(0.13)$ & $0.007^{5}$ \\
\hline $\begin{array}{l}\text { Head nurse for number of } \\
\text { units }\end{array}$ & $174 / 2.81(1.23)$ & $113 / 2.60(0.90)$ & $61 / 3.20(1.60)$ & $0.009^{5}$ \\
\hline $\begin{array}{l}\text { Physician; minutes per resident } \\
\text { per week } \\
\text { SCUEQS }^{3}\end{array}$ & $174 / 26.09(18.52)$ & $113 / 25.03(16.47)$ & $61 / 28.05(21.84)$ & $0.348^{5}$ \\
\hline \multicolumn{5}{|l|}{ Maintenance } \\
\hline $\begin{array}{l}\text { 7a Maintenance of social } \\
\text { spaces }\end{array}$ & $175 / 1.35(0.67)$ & $113 / 1.32(0.67)$ & $62 / 1.40(0.66)$ & $0.405^{6}$ \\
\hline 7b Maintenance of halls & $175 / 1.39(0.68)$ & $113 / 1.34(0.68)$ & $62 / 1.50(0.67)$ & $0.093^{6}$ \\
\hline $\begin{array}{l}\text { 7c Maintenance of resident } \\
\text { rooms }\end{array}$ & $175 / 1.34(0.68)$ & $113 / 1.31(0.72)$ & $62 / 1.40(0.61)$ & $0.526^{6}$ \\
\hline $\begin{array}{l}\text { 7d Maintenance of resident } \\
\text { bathrooms }\end{array}$ & $175 / 1.31(0.72)$ & $113 / 1.23(0.74)$ & $62 / 1.45(0.65)$ & $0.063^{6}$ \\
\hline \multicolumn{5}{|l|}{ Cleanliness } \\
\hline 8a Cleanliness of social spaces & $175 / 1.32(0.64)$ & $113 / 1.33(0.63)$ & $62 / 1.31(0.64)$ & $0.842^{6}$ \\
\hline $8 \mathrm{~b}$ Cleanliness of halls & $175 / 1.37(0.61)$ & $113 / 1.37(0.62)$ & $62 / 1.35(0.60)$ & $0.826^{6}$ \\
\hline $\begin{array}{l}\text { 9a Bodily excretion odor in } \\
\text { public areas }\end{array}$ & $175 / 1.84(0.43)$ & $113 / 1.84(0.43)$ & $62 / 1.84(0.41)$ & $0.845^{6}$ \\
\hline $\begin{array}{l}\text { 9b Bodily excretion odor in } \\
\text { residents rooms }\end{array}$ & $175 / 1.82(0.40)$ & $113 / 1.81(0.39)$ & $62 / 1.82(0.43)$ & $0.722^{6}$ \\
\hline \multicolumn{5}{|l|}{ Safety } \\
\hline $10 \mathrm{~b}$ Floor surface in halls & $175 / 1.08(0.83)$ & $113 / 0.98(0.88)$ & $62 / 1.26(0.74)$ & $0.045^{6}$ \\
\hline \multicolumn{5}{|l|}{ Lightning } \\
\hline $\begin{array}{l}12 \mathrm{~b} \text { Light intensity in activity } \\
\text { areas }\end{array}$ & $173 / 1.30(0.68)$ & $111 / 1.24(0.95)$ & $62 / 1.29(0.64)$ & $0.736^{6}$ \\
\hline $\begin{array}{l}\text { 12c Light intensity in residents } \\
\text { rooms }\end{array}$ & $175 / 0.98(0.67)$ & $113 / 0.90(0.67)$ & $62 / 1.13(0.64)$ & $0.031^{6}$ \\
\hline $\begin{array}{l}\text { Visual/tactile stimulation } \\
25 \text { b Visual stimulation } \\
\text { opportunities }\end{array}$ & $175 / 1.86(0.83)$ & $113 / 1.90(0.79)$ & $62 / 1.79(0.91)$ & $0.458^{6}$ \\
\hline \multicolumn{5}{|l|}{ Noise } \\
\hline $\begin{array}{l}\text { 31d Load speaker/intercom } \\
\text { noise }\end{array}$ & $172 / 1.91(0.40)$ & $112 / 1.88(0.46)$ & $62 / 1.97(0.26)$ & $0.176^{6}$ \\
\hline \multicolumn{5}{|l|}{ Familiarity/homelikeness } \\
\hline 19 Public areas homelike & $173 / 1.42(1.02)$ & $111 / 1.24(0.95)$ & $62 / 1.73(1.09)$ & $0.005^{6}$ \\
\hline 20 Kitchen in the unit & $175 / 0.64(0.89)$ & $113 / 0.60(0.88)$ & $62 / 0.71(0.89)$ & $0.373^{6}$ \\
\hline $\begin{array}{l}21 \text { Pictures/mementos in } \\
\text { residents room }\end{array}$ & $175 / 2.81(0.58)$ & $113 / 2.78(0.64)$ & $62 / 2.87(0.46)$ & $0.375^{6}$ \\
\hline 23 Resident appearance & $175 / 1.97(0.18)$ & $113 / 1.98(0.13)$ & $62 / 1.94(0.25)$ & $0.105^{6}$ \\
\hline \multicolumn{5}{|l|}{ Orientation } \\
\hline $\begin{array}{l}28 \mathrm{c}+\mathrm{d} \text { Current or old picture } \\
\text { of resident }\end{array}$ & $175 / 0.06(0.24)$ & $113 / 0.06(0.24)$ & $62 / 0.06(0.25)$ & $0.947^{6}$ \\
\hline SCUEQS total sum & $175 / 25.72(4.79)$ & $113 / 25.15(4.61)$ & $62 / 26.76(4.50)$ & $0.033^{5}$ \\
\hline $\mathrm{P}-\mathrm{CAT}^{4}$ total sum & $1,157 / 46.16(7.46)$ & $763 / 44.82(7.43)$ & $394 / 48.74(6.83)$ & $<0.001^{5}$ \\
\hline
\end{tabular}

${ }^{1} \mathrm{~A}$ unit is defined as a group of residents living together with a common living area and having their own care staff during daytime.

${ }^{2} \mathrm{SD}=$ Standard deviation.

${ }^{3}$ SCUEQS = Special Care Unit Environmental Quality Scale.

${ }^{4} \mathrm{P}-\mathrm{CAT}=$ Person-Centered Care Assessment Tool.

${ }^{5} t$-test.

${ }^{6}$ Mann-Whitney $U$ test. 
environment, staffing ratio, and the number of units the head nurse was leader of. All P-CAT scores except for one item - the environment feels chaotic - were higher in SCUs than in RUs. Four SCUEQS items - cleanliness of social spaces and halls, visual stimulation opportunities, and resident appearance - had higher scores in RU than in SCU, for all other SCUEQS items SCU had higher scores. Three items - floor surface in halls, light intensity in resident's rooms, and public areas homelike - in addition to the total sum score were significantly higher in SCU, indicating that SCU have a more dementia-friendly environment.

\section{Variables associated with P-CAT score}

Multilevel linear regression analyses were conducted to analyze the associations between staff variables; QPS-N variables, unit variables, and the P-CAT score (Table 3).

High job satisfaction was associated with a higher P-CAT score in the univariate analysis, as well as all the three models in the multivariate analysis. Having three years or more health-related education was not associated with a higher P-CAT score in the univariate analysis or in model 1 of the multivariate analysis, but was associated with a higher P-CAT score in models 2 and 3 of the multivariate analysis, compared to having lower education.

In the univariate analysis, all the QPS$\mathrm{N}$ subscales, except decision demands, were associated with the P-CAT score. Adjusted for staff variables and the other QPS-N subscale scores (model 2), decision demands, perception of mastery, empowering leadership, innovative climate, and perception of group work were positively associated with the P-CAT score, while quantitative demands and role conflict were negatively associated with the P-CAT score. This pattern was sustained in model 3 where unit variables were added to the model, except that decision demands were no longer significant.

In the univariate analysis, type of unit, number of beds, SCUEQS sum, and staff at daytime/patient were all associated with the P-CAT score. Adjusted for all the other variables (model 3), SCUs were associated with a higher P-CAT score compared to RUs, and a higher SCUEQS sum was associated with a higher P-CAT score.

\section{Discussion}

The main finding of this study was that high job satisfaction in care staff and care organized in small, specialized units were both strongly associated with a high level of PCC. More specifically, we found that staff with three years or more of health-related education, a lower level of quantitative demands and role conflict, a higher level of perception of mastery, empowering leadership, innovative climate, and perception of group work, in addition to a physical environment in the $\mathrm{NH}$ unit designed for people with dementia, were all associated with higher levels of PCC. To our knowledge, this is the first study exploring the complex association between PCC, organizational, NH staff and unit characteristics in Norwegian NH.

The strongest association with high levels of PCC was a high score on job satisfaction, even when adjusted for all the QPS-Nordic subscales. This finding is supported by a previous review article from 2013 (Brownie and Nancarrow, 2013), which reported that facility-specific PCC interventions were found to impact the nurses' sense of job satisfaction, a Dutch study which analyzed the association between PCC and job satisfaction, and concluded that PCC may contribute to higher job satisfaction (van den Pol-Grevelink et al., 2012), and, finally, a Swedish study, which also found that higher levels of staff job satisfaction were associated with higher levels of PCC (Sjogren et al., 2015). Together, these findings should be taken into account when planning care for residents in $\mathrm{NH}$, even though we were not able to show if the staff's job satisfaction leads to higher degree of PCC or if it is the other way around.

In the univariate analysis, both the size of the units (number of beds) and the daytime staff/patient ratio were associated with higher levels of PCC, but these associations vanished when adjusted for other factors. However, SCUs were associated with higher levels of PCC, and as the average sizes of the SCUs were smaller and SCUs had on average a higher daytime staff/patient ratio (Table 2), both the size of the unit and the staff/patient ratio were important elements explaining the association between the type of ward and PCC.

Previous studies comparing SCUs and RUs have looked at patient outcomes, such as behavior, functioning in activities of daily living, cognitive function, and quality of life, to our knowledge, no other studies have specifically investigated the effect of SCU on PCC. A review from 2013 shows that patient characteristics only to a minor extent are different in SCU compared to RU (Kok et al., 2013). Other studies have looked at quality indicators such as the use of restraints and the prescription of antipsychotics (Kirkevold and Engedal, 2008), and provision of case conferences (Palm et al., 2016). These studies show that the literature is not consistent according to quality indicators. A review from 2009 evaluating the 
Table 3. Multilevel linear regression with person-centered care assessment tool (P-CAT) sum as dependent variable

\begin{tabular}{|c|c|c|c|c|c|c|c|c|c|}
\hline \multirow[b]{2}{*}{ Staff variables } & \multirow[b]{2}{*}{$\mathrm{n}$} & \multicolumn{2}{|c|}{$\begin{array}{l}\text { UNIVARIATE } \\
\text { ANALYSIS }\end{array}$} & \multicolumn{2}{|c|}{$\begin{array}{l}\text { DATA FROM } \\
175 \text { UNITS }\end{array}$} & \multicolumn{2}{|c|}{$\begin{array}{l}\text { DATA FROM } \\
175 \text { UNITS }\end{array}$} & $\begin{array}{l}\text { DATA FROM } \\
174 \text { UNITS }\end{array}$ & $\begin{array}{l}\text { L } 3 \\
96 \\
\text { ROM } \\
\text { NITS }\end{array}$ \\
\hline & & coefficient & $\mathrm{p}$-value & coefficient & p-value & coefficient & $\mathrm{p}$-value & coefficient & $\mathrm{p}$-value \\
\hline Age & 1,132 & -0.206 & 0.175 & 0.063 & 0.704 & 0.079 & 0.601 & 0.046 & 0.761 \\
\hline Gender & 1,094 & 0.507 & 0.642 & 0.821 & 0.423 & 0.882 & 0.332 & 0.797 & 0.377 \\
\hline Job satisfaction & 1,148 & 3.235 & $<0.001$ & 3.275 & $<0.001$ & 1.451 & $<0.001$ & 1.453 & $<0.001$ \\
\hline $\begin{array}{l}3 \text { years or more health-related } \\
\text { education }\end{array}$ & 1,153 & 0.234 & 0.571 & 0.840 & 0.050 & 1.333 & 0.001 & 1.289 & 0.001 \\
\hline$\geq 75 \%$ of full time position & 1,135 & 0.183 & 0.641 & -0.506 & 0.212 & -0.543 & 0.135 & -0.477 & 0.189 \\
\hline$\overline{\text { Experience in profession }}{ }^{1}$ & 1,119 & -0.285 & 0.197 & -0.340 & 0.148 & -0.243 & 0.254 & -0.212 & 0.317 \\
\hline Advanced education & 1,157 & 0.653 & 0.132 & 0.992 & 0.021 & 0.674 & 0.082 & 0.59 & 0.125 \\
\hline \multicolumn{10}{|l|}{ QPS-Nordic ${ }^{2}$} \\
\hline QPS-N. Quantitative demands & 1,145 & -0.916 & $<0.001$ & & & -0.644 & $<0.001$ & -0.601 & $<0.001$ \\
\hline QPS-N. Decision demands & 1,145 & -0.085 & 0.391 & & & 0.222 & 0.021 & 0.173 & 0.069 \\
\hline QPS-N. Learning demands & 1,145 & -0.509 & $<0.001$ & & & 0.023 & 0.840 & 0.015 & 0.894 \\
\hline QPS-N. Perception of mastery & 1,145 & 1.210 & $<0.001$ & & & 0.260 & 0.015 & 0.260 & 0.015 \\
\hline $\begin{array}{l}\text { QPS-N. Empowering } \\
\text { leadership }\end{array}$ & 1,146 & 0.759 & $<0.001$ & & & 0.341 & $<0.001$ & 0.343 & $<0.001$ \\
\hline QPS-N. Fair leadership & 1,147 & 0.879 & $<0.001$ & & & 0.061 & 0.462 & 0.075 & 0.360 \\
\hline QPS-N. Role clarity & 1,147 & 0.931 & $<0.001$ & & & 0.009 & 0.934 & 0.034 & 0.753 \\
\hline QPS-N. Role conflict & 1,147 & -0.969 & $<0.001$ & & & -0.286 & 0.003 & -0.281 & 0.003 \\
\hline QPS-N. Innovative climate & 1,150 & 1.379 & $<0.001$ & & & 0.515 & $<0.001$ & 0.523 & $<0.001$ \\
\hline $\begin{array}{l}\text { QPS-N. Perception of group } \\
\text { work }\end{array}$ & 1,142 & 1.338 & $<0.001$ & & & 0.453 & $<0.001$ & 0.443 & $<0.001$ \\
\hline Unit variables & $n$ & & & & & & & & \\
\hline Type of unit ${ }^{3}$ & 175 & 3.825 & $<0.001$ & & & & & 1.773 & 0.002 \\
\hline Number of beds & 175 & -0.168 & 0.007 & & & & & -0.026 & 0.555 \\
\hline SCUEQS $^{4}$ sum & 175 & 0.181 & 0.020 & & & & & 0.142 & 0.005 \\
\hline Staff/patient ratio & 174 & 10.607 & 0.007 & & & & & 4.361 & 0.109 \\
\hline Head nurse/number of units & 174 & 0.438 & 0.158 & & & & & 0.303 & 0.172 \\
\hline $\begin{array}{l}\text { Physician (minutes per } \\
\text { patient) }\end{array}$ & 174 & -0.008 & 0.703 & & & & & -0.006 & 0.668 \\
\hline \multicolumn{10}{|l|}{$\mathrm{ICC}^{5}=0.341$} \\
\hline \multirow{2}{*}{\multicolumn{4}{|c|}{$\begin{array}{l}\mathrm{R}_{1}^{2} \text { (Within units) } \\
\mathrm{R}_{2}^{2} \text { (Between units) }\end{array}$}} & \multicolumn{2}{|c|}{0.166} & \multicolumn{2}{|c|}{0.348} & \multicolumn{2}{|c|}{0.346} \\
\hline & & & & \multicolumn{2}{|c|}{0.298} & \multicolumn{2}{|c|}{0.591} & \multicolumn{2}{|c|}{0.722} \\
\hline
\end{tabular}

${ }^{1}$ Experience in profession (current job) in groups in years; $0=\leq 1,1=>1-4.99,2=5-14.99,3=\geq 15$.

${ }^{2}$ QPS-Nordic $=$ The General Nordic Questionnaire for Psychosocial and Social Factors at Work.

${ }^{3}$ Type of unit; $0=$ Regular Unit (RU), 1 = Special Care Unit (SCU).

${ }^{4}$ SCUEQS = Special Care Unit Environmental Quality Scale.

${ }^{5}$ ICC $=$ Intra-Class Correlation Coefficient.

effect of SCUs concluded that it is probably more important to implement best practices than to provide a specialized care environment (Lai et al., 2009). The definitions of an SCU vary across countries and across studies, and nursing homes implement different features in the units (Palm et al., 2014), thus there are challenges in comparing studies of SCUs. In the present study, the average size of an SCU was 8.5 beds, while in a Canadian study the average size of the SCUs was 18.9 beds (Morgan et al., 2004).

A Norwegian study concluded that SCUs had fewer quality deficiencies, probably due to the smaller units and a higher staff ratio (Kirkevold and Engedal, 2008). Together with the strong association between SCU and a high level of PCC, we argue that smaller, more homelike units, with a higher staff ratio, which are dedicated to persons with dementia, are a better option for persons with dementia than RUs.

Additionally, this study shows that not only the size of the unit, but also education and job satisfaction in care staff, leadership, and environment, impact the quality of care for this vulnerable group of persons. Care staff with three years or more of health-related education had a 
stronger association with a higher level of PCC in this study, similar to what was reported by Sjøgren et al. (2015), who found that a higher proportion of staff with continuing education in dementia care at the ward were associated with higher levels of PCC. With an aging population and the warranted decrease of care staff, this finding shows that not only do we need more staff, we need more staff with high education to care for our elderly.

Quantitative demands and role conflicts were both negatively associated with PCC in the present study. Similarly, Sjøgren et al., who explored the relationship between PCC and the staffs work environment and job-related well-being, reported that NH units where staff felt supported by their leaders had higher levels of PCC (Sjogren et al., 2015). Willemse et al. also found that leader support is associated with the nursing staff's person centeredness (Willemse et al., 2015). To create a work environment where the leaders support the $\mathrm{NH}$ staff, it is important to provide PCC in NH.

The QPS-Nordic subscale perception of mastery was positively associated with PCC. This association is again supported by Sjøgren's study, which found that a lower level of stress of conscience among staff was associated with higher levels of PCC (Sjogren et al., 2015). Even though perception of mastery focuses on the degree to which a carer is content with the job (Table 1), and the scale used by Sjøgren et al. focuses on factors that gives a "troubled conscience," (Glasberg et al., 2006) these two scales have overlapping themes, and it seems reasonable to argue that to work in a unit where a carer often has a troubled conscience is the opposite to being content with their work.

One can also assume that the perception of mastery is closely linked to job satisfaction, but as job satisfaction remained strongly associated to PCC even when adjusted for all QPS-Nordic subscales, job satisfaction probably includes more than just perception of mastery.

Several studies enhance the role of leaders in promoting PCC. Brownie and Nancarrow found in a review that leadership is important in culturechange processes towards PCC, as introduction of democratized approaches to decision-making that involve residents and staff (Brownie and Nancarrow, 2013). Rokstad et al. found that leaders have a central role in drawing up a clear and consistent professional vision, being continuously supportive to the care staff and taking an active part in the care practice as role models when implementing PCC using Dementia Care Mapping (DCM) in nursing homes (Rokstad et al., 2015). The finding in the present study shows that especially "empowering leadership" is associated with PCC. Empowering leadership is a managerial style supporting and encouraging the caregivers to take the initiative and to participate in decisions. Thus, the caregivers closest to the patients have greater influence on making decisions regarding daily care. These findings are in line with the findings from a literature review conducted by Brownie and Nancarrow, who concluded that the introduction of democratized approaches to decision-making involving both staff and patients and models focusing on staff empowerment are important elements to support PCC (Brownie and Nancarrow, 2013). Kitwood also underlined the importance of staff being free to take their own decisions when taking care of persons with dementia and described this as an important part of conducting PCC (Kitwood, 1997).

In the present study, an innovative climate was associated with PCC. To our knowledge, this finding has not been reported earlier. However, the components in an innovative climate, such as taking the initiative and encouraging staff to find alternative ways to do things, corresponds with the theory of PCC (Kitwood, 1997; Brooker, 2004).

Furthermore, the present study showed that the perception of group work was positively associated with PCC. This finding is supported by Hunter et al., who found that collaboration in care is important for PCC (Hunter et al., 2015). Rokstad et al. found that leaders who participated in the daily care saw themselves as role models and encouraged the staff more than leaders not taking part in the daily care of the patients (Rokstad et al., 2015). The results of these studies (Hunter et al., 2015; Rokstad et al., 2015) support the finding of a positive association between PCC and empowered staff in the present study.

The positive association between perception of group work and PCC in the present study is supported by Hunter et al. (2015). Hunter measured PCC with self-rated measurements, creating five subscales (autonomy, personhood, knowing the person, comfort care, and support for relationships) and found that in four of the five subscales collaboration was the only environmental variable that was associated with PCC. Further, they suggested that focusing on changing organizational processes to create PCC may be more fruitful than a focus on individual behavior, concluding that collaboration in care is important to promote PCC (Hunter et al., 2015).

In a recent literature review, Chaudhury et al. (2017) stated that the physical environment of the unit plays an important role in the care of persons with dementia, both in enhancing the patient's quality of life and in the quality of care. In addition, they highlighted the influence of the unit size, the spatial layout, the homelike character, sensory 
stimulation, and specific spaces on the patients' behavior and well-being, but they emphasized that the potential of a therapeutic physical milieu is meaningfully utilized only when taking into account the unit's organizational policies and relational care practices (Chaudhury et al., 2017). These findings are supported by Brownie and Nancarrow, who in a review investigated the evidence for the impact of person-centered interventions on aged-care residents and nursingstaff support, concluding that person-centered interventions are multifactorial, where elements of environmental enhancement are included (Brownie and Nancarrow, 2013). The findings in the present study support this conclusion. As the assessment of the physical environment (measured with the SCUEQS) remains significantly associated with PCC after adjusting for size and type of ward, other variables describing the physical environment are as important as size of ward when the staff assess PCC with P-CAT. It is also worth highlighting that "Public areas homelike" was the variable that differs most between SCUs and RUs (Table 2).

It is important to underline that the staff variables and the QPS-N variables contributed more to the model than the environmental variables (Table 3, $\mathrm{R}_{1}^{2}$ and $\mathrm{R}_{2}^{2}$ ) and indicated that it is important to focus on these factors independent of type of ward.

\section{Strengths and weaknesses}

To our knowledge, this is the first study exploring the complex associations between PCC, organizational, $\mathrm{NH}$ staff and unit characteristics in Norwegian $\mathrm{NH}$. The strengths of this study are the large number of $\mathrm{NH}$ units and care staff that participated and the use of standardized and reliable assessment tools which made it possible to compare findings with other studies, both in Norway and internationally. The high number of care staff included in the study is also a strength, enabling inclusion of several potential important variables in the regression analyses. The distribution of the care-staff questionnaire was done in cooperation with the head nurse of the unit, and the procedure for returning the answers enhanced the care staff's anonymity. The physical environmental assessments (TESS$\mathrm{NH}$ ) were conducted by five researchers, which have had the same training doing the TESS-HN. The NH staff had no information about the score of the physical environment when scoring the PCAT. The high response rate from both the leaders of the unit and the care staff, $99.5 \%$ and $67.5 \%$, respectively, is a strength of the study.
There are number of limitations to this study, and we consider the complex causal pathways as the most important. The NH staff rated both PCC, their work-related psychosocial factors and job satisfaction, giving only the staffs' perception and possibly leading to biased data. A limitation of the study is that the participating units were not selected randomly, but they were a convenient sample of NHs geographically distributed throughout Norway and representing small and large units, SCUs and RUs. We used the SCUEQS to assess the physical environment in the $\mathrm{NH}$, which is an American scale developed in 2002. Although there may be differences due to cultural issues between Norway and the U.S., using a standardized instrument gives better data quality than just select arbitrary environmental variables. Thus, the SCUEQS scale is the most proper environmental scale for this study.

\section{Conclusion}

The association between PCC and several organizational, $\mathrm{NH}$ staff and unit characteristics identified in this study indicates that providing PCC in NH care is closely linked to how the staff experiences their job situation in addition to both organizational and structural factors and the physical environment. This knowledge is important for creating better care for persons with dementia, and attention needs to be given to this when planning $\mathrm{NH}$ care.

\section{Conflict of interest}

None.

\section{Description of authors' roles}

I. Røen designed the study, collected the data, and wrote the paper. $\varnothing$. Kirkevold was involved in designing the study, performed the statistical analysis, and assisted with the writing. I. Testad assisted with the writing and revised the article critically. G. Selbæk was involved in designing the study and revised the article critically for important intellectual content. K. Engedal revised the article critically for important intellectual content. S. Bergh was involved in designing the study, supervised the data collection, and assisted with the writing. All authors approved the final version. 


\section{Acknowledgments}

The Research Council of Norway funded the first author's PhD study. NHs in Hedmark, Oppland, Hordaland, and Nord-Trøndelag counties participated in the study.

We would like to thank the staff, the head nurses, and the managers in the nursing homes for participating in the study. We also thank the research nurses at Innlandet Hospital Trust for contributing in the data collection effort in the NHs.

\section{References}

Acquadro, C., Jambon, B., Ellis, D. and Marquis, P. (1996). Language and translation issues.In B. Spilker (ed.), Quality of Life and Pharmacoeconomics in Clinical Trials (pp. 575-585), 2 edn. Philadelphia: Lippincott-Raven.

Anderson, K., Bird, M., Macpherson, S. and Blair, A. (2016). How do staff influence the quality of long-term dementia care and the lives of residents? a systematic review of the evidence. International Psychogeriatrics, 28, 1263-1281.

Ballard, C. et al. (2015). Impact of antipsychotic review and nonpharmacological intervention on antipsychotic use, neuropsychiatric symptoms, and mortality in people with dementia living in nursing homes: a factorial cluster-randomized controlled trial by the well-being and health for people with dementia (WHELD) program. American fournal of Psychiatry, 173(3), 252-262.

Brooker, D. J., Argyle, E., Scally, A. J. and Clancy, D. (2011). The enriched opportunities programme for people with dementia: a cluster-randomised controlled trial in 10 extra care housing schemes. Aging and Mental Health, 15, 1008-1017.

Brooker, D. (2004). What is person-centered care in dementia? Reviews in Clinical Gerontology, 13, 215-222.

Brownie, S. and Nancarrow, S. (2013). Effects of person-centered care on residents and staff in aged-care facilities: a systematic review. Clinical Interventions in Aging, $8,1-10$.

Chaudhury, H., Cooke, H. A., Cowie, H. and Razaghi, L. (2017). The influence of the physical environment on residents with dementia in long-term care settings: a review of the empirical literature. Gerontologist, doi:10.1093/geront/gnw259.

Chenoweth, L. et al. (2009). Caring for aged dementia care resident study (CADRES) of person-centred care, dementia-care mapping, and usual care in dementia: a cluster-randomised trial. The Lancet Neurology, 8, 317-325.

Dallner, M., Elo, A.-L., Gamberale, F., Hottinen, V., Knardahl, S. and Lindström, K. (2000). Validation of the General Nordic Questionnaire (QPSNordic) for Psychological and Social Factors at Work. Copenhagen: Nordic Council of Ministers, Nord.

De Silva, D. (2014). Helping Measure Person-Centred Care. London: The Health Foundation.

Edvardsson, D., Fetherstonhaugh, D., Nay, R. and Gibson, S. (2010). Development and initial testing of the person-centered care assessment tool (P-CAT). International Psychogeriatrics, 22, 101-108.

Edvardsson, D. and Innes, A. (2010). Measuring person-centered care: a critical comparative review of published tools. Gerontologist, 50, 834-846.

Efron, B. and Tibshirani, R. J. (1994). An Introduction to the Bootstrap. London: Taylor \& Francis.

Fossey, J. et al. (2006). Effect of enhanced psychosocial care on antipsychotic use in nursing home residents with severe dementia: cluster randomised trial. BMF, 332, 756-761.

Glasberg, A. L. et al. (2006). Development and initial validation of the stress of conscience questionnaire. Nursing Ethics, 13, 633-648.

Hunter, P. V., Hadjistavropoulos, T., Thorpe, L., Lix, L. M. and Malloy, D. C. (2015). The influence of individual and organizational factors on person-centred dementia care. Aging and Mental Health, 20, 1-9.

Kirkevold, O. and Engedal, K. (2008). Quality of care in Norwegian nursing homes-deficiencies and their correlates. Scandinavian fournal of Caring Sciences, 22, 560-567.

Kitwood, T. (1997). Dementia Reconsidered: The Person Comes First. Buckingham, UK: Open University Press.

Kok, J. S., Berg, I. J. and Scherder, E. J. (2013). Special care units and traditional care in dementia: relationship with behavior, cognition, functional status and quality of life - a review. Dementia and Geriatric Cognitive Disorders Extra, 3, 360-375.

Lai, C. K., Yeung, J. H., Mok, V. and Chi, I. (2009). Special care units for dementia individuals with behavioural problems. The Cochrane Database of Systematic Reviews, Article ID: CD006470.

Li, J. and Porock, D. (2014). Resident outcomes of person-centered care in long-term care: a narrative review of interventional research. International fournal of Nursing Studies, 51, 1395-1415.

Manthorpe, J. and Samsi, K. (2016). Person-centered dementia care: current perspectives. Clinical Interventions in Aging, 11, 1733-1740.

Morgan, D. G., Stewart, N. J., D'arcy, K. C. and Werezak, L. J. (2004). Evaluating rural nursing home environments: dementia special care units versus integrated facilities. Aging $\mathcal{E}$ Mental Health, 8, 256-265.

Palm, R., Bartholomeyczik, S., Roes, M. and Holle, B. (2014). Structural characteristics of specialised living units for people with dementia: a cross-sectional study in German nursing homes. International fournal of Mental Health Systems, 8, 39.

Palm, R., Trutschel, D., Simon, M., Bartholomeyczik, S. and Holle, B. (2016). Differences in case conferences in dementia specific vs traditional care units in German nursing homes: results from a cross-sectional study. fAMDA, 17, 91.e9-13.

Rokstad, A. M., Engedal, K., Edvardsson, D. and Selbaek, G. (2012). Psychometric evaluation of the Norwegian version of the person-centred care assessment tool. International fournal of Nursing Practice, 18, 99-105.

Rokstad, A. M., Vatne, S., Engedal, K. and Selbaek, G. (2015). The role of leadership in the implementation of person-centred care using dementia care mapping: a study in three nursing homes. Fournal of Nursing Management, 23, 15-26. 
Selbaek, G., Kirkevold, O. and Engedal, K. (2007). The prevalence of psychiatric symptoms and behavioural disturbances and the use of psychotropic drugs in Norwegian nursing homes. International fournal of Geriatric Psychiatry, 22, 843-849.

Sjogren, K., Lindkvist, M., Sandman, P. O., Zingmark, K. and Edvardsson, D.(2015). To what extent is the work environment of staff related to person-centred care? a cross-sectional study of residential aged care. Fournal of Clinical Nursing, 24, 1310-1319.

Sloane, P. D. et al. (2002). The therapeutic environment screening survey for nursing homes (TESS-NH): an observational instrument for assessing the physical environment of institutional settings for persons with dementia. The fournals of Gerontology. Series B, Psychological Sciences and Social Sciences, 57, S69-78.

Testad, I. et al. (2014). The value of personalized psychosocial interventions to address behavioral and psychological symptoms in people with dementia living in care home settings: a systematic review. International Psychogeriatrics, 26, 1083-1098.
Testad, I., Mikkelsen, A., ballard, C. and Aarsland, D. (2010). Health and well-being in care staff and their relations to organizational and psychosocial factors, care staff and resident factors in nursing homes. International Fournal of Geriatric Psychiatry, 25, 789-797.

Van den pol-grevelink, A., Jukema, J. S. and Smits, C. H. (2012). Person-centred care and job satisfaction of caregivers in nursing homes: a systematic review of the impact of different forms of person-centred care on various dimensions of job satisfaction. International fournal of Geriatric Psychiatry, 27, 219-229.

Wilberforce, M., Challis, D., Davies, L., Kelly, M. P., Roberts, C. and Loynes, N. (2016). Person-centredness in the care of older adults: a systematic review of questionnaire-based scales and their measurement properties. BMC Geriatrics, 16, 63.

Willemse, B. M., De Jonge, J., Smit, D., Visser, Q., Depla, M. F. and Pot, A. M. (2015). Staff's person-centredness in dementia care in relation to job characteristics and job-related well-being: a cross-sectional survey in nursing homes. Fournal of Advanced Nursing, 71, 404-416. 